Original Research Article

\title{
A study of hypoglycemic effect of Caesalpinia bonduc extract on alloxan induced diabetic albino rats
}

Department of Pharmacology, Karnataka Institute of Medical Sciences, Hubballi, Karnataka, India

Received: 12 July 2017

Revised: 18 July 2017

Accepted: 05 August 2017

*Correspondence to:

Dr. Reshma Nadaf,

Email: dr_reshmanadaf@ yahoo.com

Copyright: (C) the author(s), publisher and licensee Medip Academy. This is an openaccess article distributed under the terms of the Creative Commons Attribution NonCommercial License, which permits unrestricted noncommercial use, distribution, and reproduction in any medium, provided the original work is properly cited.

\author{
Reshma Nadaf*
}

\begin{abstract}
Background: The objective of the study was to scientifically investigate the oral hypoglycemic activity of Caesalpinia bonduc on Alloxan induced diabetic albino rats. To compare the hypoglycemic effect of Caesalpinia bonduc with that of the standard drug Glibenclamide used in the treatment of diabetes mellitus.

Methods: Adult healthy albino rats of wister strain of either sex weighing 150$200 \mathrm{gms}$ were included in the study. The animals were divided into 4 groups namely control, diabetic control, standard and test groups with 6 animals in each group. Diabetes was chemically induced using alloxan to produce hyperglycemia in rats. Standard drug Glibenclamide suspended in gum acacia was administered for standard group. Test drug Caesalpinia bonduc was administered for test group. Morning around 9 a.m. blood glucose levels were recorded on $1^{\text {st }}, 3^{\text {rd }}, 7^{\text {th }}$, $14^{\text {th }}, 21^{\text {st }}$, and $28^{\text {th }}$ days.

Results: The control group of rats showed no variation. The diabetic control rats showed consistent hyperglycemia. Comparing the test drug Caesalpinia bonduc to the standard drug Glibenclamide, the test drug was 1.38 times more efficacious than the standard.

Conclusions: The alcoholic extract of Caesalpinia bonduc (seeds) has shown more anti diabetic activity by lowering the blood glucose levels in diabetic rats significantly. These findings suggest that hypoglycemic potential of the test compound Caesalpinia bonduc is promising and found to be more significant than the standard compound.
\end{abstract}

Keywords: Caesalpinia bonduc, Diabetes mellitus, Glibenclamide

\section{INTRODUCTION}

Diabetes mellitus is a global public health problem of epidemic proportions, and its incidence is on rise. DM has risen more dramatically over past two decades and is expected to rise more rapidly due to increase in obesity and decrease in physical activity. During year 2014, the number of cases of diabetes worldwide was estimated to be around 422 million, of these more than 90 percent are type 2 diabetes. ${ }^{1}$

Diabetes is a chronic metabolic disorder associated with accelerated atherosclerosis and a prothrombotic state, markedly increasing the risk of MI, stroke, peripheral arterial disease and heart failure. $75 \%$ of individuals with diabetes die from cardio-vascular disease and diabetic subjects without known coronary artery disease have the same cardiovascular prognosis as non diabetic subjects with CAD. It is also a leading cause of adult blindness, end stage renal disease and non traumatic leg amputation. Death rates of diabetes have increased by $30 \%$ during same period time. The annual cost of diabetes in terms of medical care and lost productivity exceeds 130 billion dollars in U.S alone.

The American Diabetes Association (ADA) has estimated that in US alone if $80 \%$ of individuals with type 2 diabetes 
achieved 5 recommended ADA treatment goals over next 30 years there would be 5 million fewer heart attacks, 1.2 million fewer cases of kidney failure, 1.8 million fewer cases of blindness and 1.8 million fewer premature deaths. In addition, more than 150 billion dollars in medical costs can be saved.

Long before the use of insulin became common, indigenous remedies were used for the treatment of DM. There has been increased in demand from patients for the use of natural products with anti diabetic activity. The available herbal products and oral hypoglycemic drugs and insulin injections are associated with risk of hypoglycemia and impairment of hepatic and other body functions. Due to which Alternative therapies for diabetes have become increasingly popular like medicinal herbs, nutritional supplementation, and acupuncture and hot-tub therapy. ${ }^{2}$

\section{Medicinal herbs}

Herbal medicines are the oldest remedies known to mankind. Ayurveda and other Indian literature mention the uses of plants in treatment of various ailments. India has around 45000 plant species and among them several thousands have been claimed to have medicinal properties.

As per Ayurveda and Hindu literature like Charka Samhita, Madhav nidhan and Astang Sanghara there are about 600 plants which are supposed to have anti diabetic property, only a small number of these have received scientific and medical evaluation.

Substantial efforts have been made in recent years to identify new natural and synthetic anti diabetics. The search for more effective and safer hypoglycemic agents continues to be an important research area.

Currently available synthetic anti diabetic agents produce serious side effects like hypoglycemic coma, hepatorenal disturbance. $^{3}$

Moreover, they are not safe in pregnancy hence the search for safer and more effective hypoglycemic agents has continued. ${ }^{4}$ Several investigations have been conducted and many plants have shown a positive activity.

It is rightly said by Dr. Pierre that "it is important to explore ways of dealing with diabetes that are in harmony with aboriginal people's culture and lifestyle".

Caesalpinia bonduc is one such plant that has anti diabetic potential. There are numerous plants mentioned in the indigenous system of health care but still await scientific enquiry. There are many grey areas which need substantial amount of work in case of herbal anti diabetics. Hence here the study will be undertaken to scientifically investigate the hypoglycemic effect of Caesalpinia bonduc. ${ }^{5}$

Presently available drugs including herbs are not completely fulfilling the criteria of total management of diabetes for Ex. Glibenclamide, very good oral hypoglycemic drug but chances of developing of hypoglycemia is more and also may not be helpful to prevent or postpone complications of DM. Hence in this study an earnest attempt is being made to identify the oral hypoglycemic potentiality of Caesalpinia bonduc which may give an insight for the further studies.

\section{METHODS}

- Chemicals: Alloxan monohydrate, Glibenclamide, Gum acacia, Sodium chloride and semi solid alcoholic extract of seeds of Caesalpinia bonduc.

- Animals: Albino rats.

- Equipments: Mouth gag, Oral feeding tube, Tuberculin syringe $(1 \mathrm{ml})$ and Glucometer.

\section{Chemicals}

Alloxan monohydrate

- It is clearly soluble in water.

- $\quad$ It should be stored between 0-50C.6

- Structure: 2, 4, 5, 6- Tetraoxypyrimidine 5, 6Dioxyuracil- $\mathrm{C}_{4} \mathrm{H}_{2} \mathrm{~N}_{2} \mathrm{O}_{4} \cdot \mathrm{H}_{2} \mathrm{O}$.

- 2 grams of Alloxan monohydrate is dissolved in $100 \mathrm{ml}$ of sterile $0.9 \%$ Sodium chloride to obtain $2 \%$ Alloxan monohydrate solution.

\section{Gum acacia}

Gum Acacia is the dried gummy exudate obtained from bark of Acacia arabica or other African species of acacia. This is used as a suspending agent for the oral administration of the standard and test compound, concentration being $2 \%$.

\section{Glibenclamide}

Glibenclamide belongs to second-generation sulfonylureas. It is taken as a standard drug. Results obtained are used to compare with the test drug.

\section{Caesalpinia bonduc}

In this study semi solid methanolic extract obtained from seeds of Caesalpinia bonduc has been taken up for the investigation of hypoglycemic effect. Caesalpinia bonduc (L) Roxb; belong to family Caesalpiniaceae. Synonyms are C. Crista L, C. bonducella flene and Guilandina bonduc $\mathrm{W}$ and $\mathrm{A}$. Their common names are bonduc, fever nut, Indian filbert, mollusca nut, physic nut, nicker bean. In Kannada it is known as Gajjuga / Gejjege balli. ${ }^{7,8}$

\section{Animals}

Adult healthy albino rats of Wistar strain of either sex weighing 150-200gms (Pregnant animals were excluded in this study). 
In animals Alloxan and Streptozotocin cause $\beta$ cell cytolysis within 4-8 hours. ${ }^{9,10}$ This effect is mostly due to interaction with protein synthesis associated with cell membrane and may be mediated by depression of nicotinamide adenine nucleotide levels in $\beta$ cells.

The animals were divided into 4 groups namely control, diabetic control, standard and test groups, with 6 animals in each group. Extra 6 animals were kept as a reserve incase if some animals did not develop hyperglycemia to the requisite level. Hence in total 30 animals are used, in which 24 animals were induced with diabetes and of them only 18 rats were used in experimentation as control, diabetic control, standard and test group.

\section{Equipments}

- Mouth gag: To facilitate the introduction of oral feeding tube into the stomach of the rat.

- Oral feeding tube (small): Used for oral administration of gum acacia, standard and the test compounds

- $\quad$ Tuberculin syringe $(1 \mathrm{ml})$ : Used for injecting Alloxan monohydrate into the peritoneal cavity.

- Glucometer: The Glucometer used in this study is the Sure Step Life scan for measuring the blood glucose level of the capillary blood.

In the present study diabetes was chemically induced using alloxan to produce hyperglycemia in rats. Here the alloxan monohydrate was administered intraperitoneally under aseptic precaution to induce diabetes mellitus 5 days before the experiment. The blood glucose was measured with the help of Glucometer.

Adult healthy albino rats of Wistar strain of either sex weighing 150-200gms were used in this study. (Pregnant animals were excluded from the study). Animals were procured from the Central animal facility, J.S.S. Medical College, Mysore. Animals were fed with commercial pellet diet and water ad libitum throughout the experiment. Animals were acclimatized to the laboratory conditions before carrying out any experimental work.

Animals were divided into four groups, six animals in each group. They were named as control, diabetic control, standard and test groups and were kept separately in different cages, with 2 rats in each cage.

Blood glucose level was recorded in all rats in the morning around 9 a.m by collecting the blood through the tail vein by cutting the tip of the tail. Blood glucose was estimated using glucometer.

\section{Induction of diabetes}

Following an overnight fast, diabetic control, standard and test animals were injected intraperitoneally approaching the peritoneal cavity through the left lower quadrant of the ventral surface of abdominal cavity, with freshly prepared
Alloxan monohydrate ( $2 \%$ solution, dissolved in $0.9 \%$ sodium chloride) in a dose of $150 \mathrm{mg} / \mathrm{kg}$ body weight.

Animals were carefully observed for first 24 hours following the injection for any evidence of allergic reactions, behavioural changes, convulsions and hypoglycemic attacks. No untoward reaction was observed in any animal.

Blood glucose level was recorded daily morning at around 9.00 a.m for 1 week. Animals developed stable hyperglycemia after 5 days. Only those animals with blood glucose level more than $200 \mathrm{mg} / \mathrm{dl}$ were selected for the study. Later they were divided into 3 groups:

- Diabetic control group,

- Standard group,

- Test group.

\section{Control group (G1)}

Here non-diabetic normal animals which have not received alloxan were taken as control group for study. Animals were fed with $0.5 \mathrm{ml}$ of $2 \%$ Gum acacia suspension daily for 28 days through oral route. Blood glucose levels were recorded on 0 day before the administration of gum acacia, then on $1^{\text {st }}, 3^{\text {rd }} 7^{\text {th }}, 14^{\text {th }}, 21^{\text {st }}$, and $28^{\text {th }}$ days.

\section{Diabetic control group (G2)}

The blood glucose levels of diabetic animals of this group were recorded at around 9 am before giving Gum acacia. This value was considered as blood glucose value of 0 day. Later the animals were fed with $0.5 \mathrm{ml}$ gum acacia $2 \%$ suspension orally, daily in the morning for 28 days. Blood glucose levels were recorded on $1^{\text {st }}, 3^{\text {rd, } 7 \text { th }}, 14^{\text {th }}, 21^{\text {st }}$, and $28^{\text {th }}$ days. Animals were observed carefully for the evidence of any behavioral changes, hyperglycemia, convulsions etc.

\section{Standard group (G3)}

The blood glucose levels of diabetic animals of this group were recorded at around 9 am before the administration of the standard drug Glibenclamide suspended in gum acacia, this value was considered as blood glucose value of 0 day. Later the animals were fed with Glibenclamide $0.5 / \mathrm{kg}$ body weight suspended in $2 \%$ of gum acacia orally, daily in the morning for 28 days. Blood glucose levels were recorded on $1^{\text {st }}, 3^{\text {rd }} 7$ th $, 14^{\text {th }}, 21^{\text {st }}$, and $28^{\text {th }}$ days. Animals were observed carefully for the evidence of any behavioral changes, hypoglycemia, convulsions etc.

\section{Test group (G4)}

The blood glucose levels of diabetic animals of this group were recorded at around 9 am before the administration of the test drug Caesalpinia bonduc $0.5 / \mathrm{kg}$ body weight suspended in $2 \%$ of gum acacia, this value was considered as blood glucose value of 0 day. Later the animals were fed 
with Caesalpinia bonduc in a dose of $200 \mathrm{mg} / \mathrm{kg}$ body weight (i.e. $40 \mathrm{mg}$ in $0.5 \mathrm{ml}$ ) mixed in $2 \%$ Gum acacia orally, daily in the morning for 28 days. Blood glucose levels were recorded on $1^{\text {st }}, 3^{\text {rd, } 7 \text { th }}, 14^{\text {th }}, 21^{\text {st }}$, and $28^{\text {th }}$ days. Animals were observed carefully for the evidence of any behavioral changes, hypoglycemia and convulsions.

\section{RESULTS}

The mean values of blood glucose levels and standard deviations in different groups of animals is shown in Figure 1.

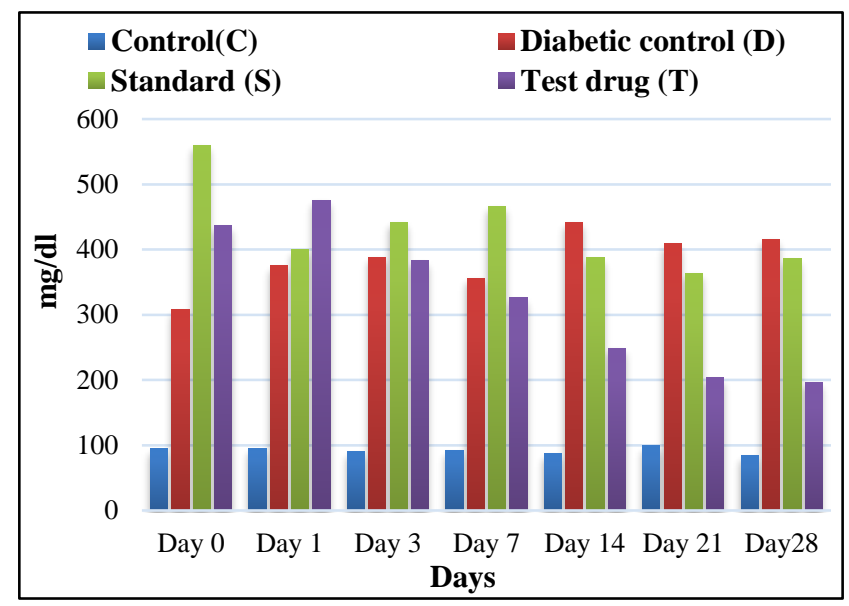

Figure 1: Mean values of blood glucose levels in different groups of animals.

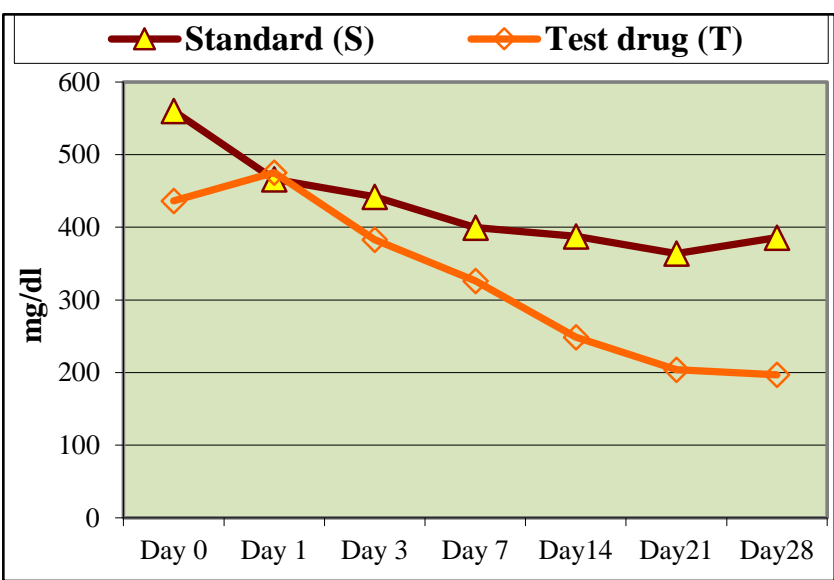

$\mathrm{X}$ - Axis shows the number of days

$\mathrm{Y}$ - Axis shows the blood glucose level in $\mathrm{mg} / \mathrm{dl}$

Figure 2: Comparison of mean blood glucose levels between standard and test groups.

Animals are divided into 4 groups (Control rats, Diabetic control, Standard group and Test group), each group consisted of 6 animals.

\section{Control rats}

Mean values of blood glucose levels range between 94.67 on Day 0 to $84.00 \mathrm{mg} / \mathrm{dl}$ on Day 28 .
Not much variation occurred throughout the experiment.

\section{Diabetic control group}

In untreated diabetic control rats, the blood glucose levels increased gradually from $307.83 \mathrm{mg} / \mathrm{dl}$ on 0 day to 375.55 on Day 1 later to $415.83 \mathrm{mg} / \mathrm{dl}$ on $28^{\text {th }}$ day.

Difference between the blood glucose levels between:

- $\quad$ D0 and D1 $=67.67 \mathrm{mg} / \mathrm{dl}$

- $\quad$ D1 and D28 = 40.33mg/dl

- $\quad$ D0 and D28 = 108mg/dl

Showing an increase in the blood glucose value.

\section{Standard group}

In the Glibenclamide treated rats the mean blood glucose level was $560.17 \mathrm{mg} / \mathrm{dl}$ on 0 Day, which reduced to $466.66 \mathrm{mg} / \mathrm{dl}$ on day 1 , and then later it steadily decreased to $363.83 \mathrm{mg} / \mathrm{dl}$ on the $21^{\text {st }}$ day, after which slight increase in blood glucose level was observed on $28^{\text {th }}$ day (386mg/dl).

Here there is persistent reduction of blood glucose level from D1 to D 21, a considerable good reduction in blood glucose level from D0 to D28.

Difference between the blood glucose levels between:

- $\quad$ D0 and D1 $=93.5 \mathrm{mg} / \mathrm{dl}$

- $\quad \mathrm{D} 1$ and D28 = 80.66mg/dl

- D0 and D 21= $196.34 \mathrm{mg} / \mathrm{dl}$

- $\quad$ D0 and D28 = $174.17 \mathrm{mg} / \mathrm{dl}$

The difference in the blood glucose levels between Day 0 to Day 1 is $93.51 \mathrm{mg} / \mathrm{dl}$ showing that the standard drug Glibenclamide has immediate hypoglycemic action hence there immediate lowering of the blood glucose.

While the blood glucose level difference between Day 1 to Day 28 is 80.66 showing the prolonged action is not as significant as acute hypoglycemic action, whereas the overall difference between BGL between Day 0 to Day 28 is $174.17 \mathrm{mg} / \mathrm{dl}$ thus this shows the total oral hypoglycemic efficacy of Glibenclamide in the study.

\section{Test group}

In the Caesalpinia bonduc treated group the blood glucose level on Day 0 was $436.5 \mathrm{mg} / \mathrm{dl}$, which increased to $475.33 \mathrm{mg} / \mathrm{dl}$ on day1, showing that the test drug did not have any hypoglycemic activity on Day1 indicating delayed onset of action, after which on Day 3 blood glucose level receded to $382.83 \mathrm{mg} / \mathrm{dl}$ and later there was persistent reduction of blood glucose level from Day 3 to Day 28 where the blood glucose level reached 196.92 $\mathrm{mg} / \mathrm{dl}$ on the $28^{\text {th }}$ day. 
Difference between the blood glucose levels between:

$\begin{array}{ll}\text { - } & \mathrm{D} 0-\mathrm{D} 1=-38.83 \mathrm{mg} / \mathrm{dl} \\ \text { - } & \mathrm{D} 1-\mathrm{D} 3=92.5 \mathrm{mg} / \mathrm{dl} \\ \text { - } & \mathrm{D} 3-\mathrm{D} 28=185.91 \mathrm{mg} / \mathrm{dl} \\ \text { - } & \mathrm{D} 1-\mathrm{D} 28=278.41 \mathrm{mg} / \mathrm{dl} \\ \text { - } & \mathrm{D} 0-\mathrm{D} 28=239.58 \mathrm{mg} / \mathrm{dl}\end{array}$

[-] sign $\rightarrow$ indicates the increase in the blood glucose level.

The difference in the blood glucose levels between Day 0 to Day 1 is $-38.83 \mathrm{mg} / \mathrm{dl}$ showing that the test drug Caesalpinia bonduc has no immediate action on lowering the blood glucose. While the blood glucose level difference between Day 1 to Day 28 is $278.41 \mathrm{mg} / \mathrm{dl}$ showing the delayed onset and sustained effect of action.

The above data shows that there is considerable good hypoglycemic effect of the herbal drug extract Caesalpinia bonduc (200mg/kg body weight) is comparable to that of the standard drug Glibenclamide $(0.5 \mathrm{mg} / \mathrm{kg}$ body weight). This shows that Caesalpinia bonduc is $137.56 \%$ more efficacious when compared to Glibenclamide and Caesalpinia bonduc is 1.38 times more efficacious compared to the standard drug Glibenclamide.

Considering the overall reduction of BGL from Day 0 to Day $28(174.17 \mathrm{mg} / \mathrm{dl})$ with the standard drug to be $100 \%$.

Then we have to find out the $\%$ for blood glucose value 239.58 .

Which is $100 \times 174.17 / 239.58=137.56 \%$.

The standard drug shows significant variation during the course of the experiment from 0 day to $28^{\text {th }}$ day. $(560.17 \mathrm{mg} / \mathrm{dl}$ to $386.00 \mathrm{mg} / \mathrm{dl})$. The difference in the values is $174.17 \mathrm{mg} / \mathrm{dl}$ of blood glucose.

The test group shows significant variation during the course of the experiment from 0 to $28^{\text {th }}$ day that is from blood glucose level of $436.5 \mathrm{mg} / \mathrm{dl}$ to $196.92 \mathrm{mg} / \mathrm{dl}$. The difference in the blood glucose value is $239.58 \mathrm{mg} / \mathrm{dl}$.

The above data shows that the test drug Caesalpinia bonduc is more efficacious than the standard drug under experimental conditions.

Difference in the blood glucose value in between Day 0 and Day 28 in different groups of animals.

- In diabetic control group of rats $\rightarrow 107.12 \mathrm{mg} / \mathrm{dl}$

- In the standard group of rats $\rightarrow 174.17 \mathrm{mg} / \mathrm{dl}$

- In the test group of rats $\rightarrow 239.58 \mathrm{mg} / \mathrm{dl}$

The mean values of blood glucose levels in different groups of animals is shown in Figure 1.
Comparison of mean blood glucose levels between standard and test groups is depicted in Figure 2.

The line diagram indicates that the standard drug shows maximum reduction in blood glucose level by $1^{\text {st }}$ day and the reduction in the blood glucose level is not so significant with respect to the test drug, rather the test drug showed a slight increase in blood glucose level by $1^{\text {st }}$ day later the blood glucose level significantly and steadily decreased by $28^{\text {th }}$ day.

Indicating the standard has good immediate than prolonged hypoglycemic action whereas the test drug has more significant and better prolonged hypoglycemic action than immediate action.

\section{DISCUSSION}

Type 2 Diabetes mellitus is a chronic metabolic disease that has a significant impact on the health, quality of life and life expectancy of patients, as well as on the health care system. The effective and essential means to control raised blood glucose are exercise, diet and weight reduction which are considered to be the prime means of improving glucose homeostasis. ${ }^{11}$

Primary prevention suffers due to difficulties in early detection of impaired fasting glucose and impaired glucose tolerance, inadequate lifestyle modification, lack of totally safe yet effective drugs for diabetes prevention and everelusive consensus regarding use of these medications i.e. oral hypoglycemic agents like biguanides, sulfonylureas etc. and insulin injection necessary in many patients either alone or with oral hypoglycemics as and when the condition arises. ${ }^{12,13}$

The presently available drugs including herbs are not completely fulfilling the criteria of management of diabetes mellitus. For example. Glibenclamide is a very good oral hypoglycemic drug but chances of developing hypoglycemia are more and also may not be helpful to prevent or postpone complications of Diabetes mellitus.

Currently available synthetic anti diabetic agents produce serious side effects and cannot be used in pregnancy hence investigations for medicinal plants with hypoglycemic actions have gained momentum. Several investigations have been conducted and many plants have shown positive activity. Caesalpinia bonduc is one such medicinal plant used traditionally for treatment of diabetes. ${ }^{14}$

Hence here in this study an earnest attempt is being made to identify oral hypoglycemic potentiality of Caesalpinia bonduc which may give an insight for further studies. Caesalpinia bonduc is used by traditional healers to treat Diabetes mellitus, the systematic scientific studies to validate its effect has been investigated in this study for its hypoglycemic effects. The results thus obtained were compared with hypoglycemic effect of Glibenclamide. 
The standard groups of rats were treated with Glibenclamide showed a steady decrease in blood glucose levels from $560.17 \mathrm{mg} / \mathrm{dl}$ on Day 0 before administration of drug and 466.33 on day 1 to $363.83 \mathrm{mg} / \mathrm{dl}$ on the $21^{\text {st }}$ day, after which slight increase in blood glucose level was observed on $28^{\text {th }}$ day. $(386 \mathrm{mg} / \mathrm{dl})$, thus indicating that the standard drug has a good immediate than prolonged hypoglycemic action.

The test group treated with Caesalpinia bonduc showed blood glucose levels of $436.5 \mathrm{mg} / \mathrm{dl}$ on Day 0 before administration of drug and $475.33 \mathrm{mg} / \mathrm{dl}$ on the $1^{\text {st }}$ day then there was steady decrease upto $196.92 \mathrm{mg} / \mathrm{dl}$ on Day 28 , indicating a delayed onset of action, and more significant and prolonged than immediate hypoglycemic action.

Statistical analysis was done using paired students t-test, $\mathrm{t}$ values obtained in each group were compared with $\mathrm{P}$ values (Standard table value of ' $\mathrm{t}$ ') at 10 degree of freedom for $0.05(5 \%)$ level of significance i.e., $\quad[\mathrm{P}<0.05$ (Significant) and $\mathrm{P}>0.05$ (not significant)]. The values were found to be statistically significant i.e. $\mathrm{P}<0.05$. Percentage reduction of blood glucose levels at the end of the experiment were $31.09 \%$ and $54.89 \%$ with the standard drug and test drug respectively. This clearly indicates that test drug is found to be more efficacious than the standard Glibenclamide.

The hypoglycemic effect of Caesalpinia bonduc was more significant to that of Glibenclamide in diabetic albino rats.

The above results indicate that alcoholic extract of Caesalpinia bonduc (seeds) has significant and sustained hypoglycemic activity action persisting till last day $\left(28^{\text {th }}\right.$ day). The difference in the blood glucose readings for test between D0 to D28 is $239.58 \mathrm{mg} / \mathrm{dl}$ and of standard the difference in D0 to D28 reading is $174.17 \mathrm{mg} / \mathrm{dl}$, when compared clearly indicate that test is 1.38 times more potent under the experimental dosage.

These findings suggest that hypoglycemic potential of the test compound Caesalpinia bonduc is promising and found to be more significant than the standard compound. Hence it may play an important role in management and preventing the progression of the disease which has not been possible till now with any other anti- diabetic agents.

Further studies in this respect along with long term safety studies and post marketing surveillance are necessary to add this novel drug to the existing ones for overall management of type 2 DM.

Funding: No funding sources

Conflict of interest: None declared
Ethical approval: The study was approved by the Institutional Ethics Committee

\section{REFERENCES}

1. Park K. Diabetes mellitus. Parks textbook of preventive and social medicine. $24^{\text {th }}$ Edi. Jabalpur: M/S Banarsidas Bhanot Publishers; 2017:411.

2. Adithan C. pharmacological research in India, 19721995. An analysis based on IPS conference. Indian J Pharmacol. 1996;28:125-8.

3. Suba V, Murugesan T, Arunachalam G, Mandal SC. Anti diabetic potential of Bacleria lupilina extracts in rats. Phytomed. 2004;11:202-5.

4. Grover JK, Yadav, Vats V. medicinal plants of India with anti diabetic potential. J. Ethnopharmacology. 2002;81:81-100.

5. Sharma SR, Dwiwedi SK, Swaroop D. Hypoglycemia, anti hyperglycemic activity and hypoglycemic activity of Caesalpinia bonduc seeds and seeds in rats; J Ethnopharmacol; 1997:58(1):39-44.

6. Doux SP, Woodley SE, Palton NJ, Wilson GL. Mechanism of nitrosourea induced b- cell damage: Alteration in DNA. Diabetes. 1986;35:866-72.

7. Chakrabarty S, Biswar TK. Antidiabetic activity of Caesalpinia bonduc. J Etnopharmacol. 2005;97(1):81100.

8. Grover JK, Yadav S, Vali V. Medicinal plants of India with antidiabetic potential. J Ethnopharmacol. 2002;81(1):117-22.

9. Cohen G, Heikkila RE. Acute effects of Alloxan on metabolism and insulin secretion of beta cells. Journal Biol Exptl, 1974;38:249-51.

10. Junad A. Diabetogenic action of Streptozotocin. J clin Invest. 1969;126:201-5.

11. Dey L, Attele AS, Yuan CS. Alternative therapies for type 2 Diabetes. Alternative Medicine Review. 2002;7(1):45-58.

12. Gujral VK. Oral hypoglycemic agents: where do we stand today?. Medicine Update. 2008;18:441-51.

13. Tripathi KD. Insulin, Oral Hypoglycaemic drugs and glucagon. Essentials of Medical Pharmacology. $7^{\text {th }}$ Ed. New Delhi: Jaypee; 2013:258-281.

14. Parameshwar S, Srinivasan KK, Mallikarjun C. Oral antidiabetic activity of different extracts of Caesalpinia bonduc seeds kernels. J Pharmaceutical biology. 2002;40(8):590-5.

Cite this article as: Nadaf R. A study of hypoglycemic effect of Caesalpinia bonduc extract on alloxan induced diabetic albino rats. Int $\mathrm{J}$ Basic Clin Pharmacol 2017;6:2153-8. 